\title{
HERMENÊUTICA ECOFEMINISTA E ECOTEOLOGIA. INTERFACES
}

\author{
Ecofeminist Hermeneutics and Ecotheology. Interfaces
}

\author{
Afonso Murad *
}

RESUMO: O ecofeminismo assume importância crescente como significativa corrente de pensamento e ativismo de gênero e socioambiental. Ele articula prática e teoria, critica o patriarcalismo, o androcentrismo e o neoliberalismo, e propõe um modelo de compreensão do ser humano baseado na reciprocidade, na cooperação e no amor à Terra. Tais características não foram ainda acolhidas suficientemente na teologia. A pesquisa visa mostrar como o ecofeminismo contribui para o avanço da ecoteologia latino-americana, devido à hermenêutica própria, à antropologia inclusiva, à linguagem que integra razão e emoção, conceitos e narrativas, e à valorização do cuidado das pessoas fragilizadas e da Casa Comum. $\mathrm{O}$ artigo inicia-se com um nivelamento conceitual. Apresenta os pontos chaves do ecofeminismo e sua forma de elaborar o conhecimento. Demonstra como a teologia ecofeminista desenvolve uma síntese criativa de elaboração conceitual, protagonismo feminino, luta em defesa das mulheres e da biosfera e espiritualidade libertadora. Conclui apresentando as diversas interfaces entre ecofeminismo e ecoteologia. Uma teologia ecológica e feminista fecunda a prática e a teorias cristãs, pois relê com categorias atuais a bíblia e a Tradição, acolhe as intuições básicas da teologia da libertação, associa a conversão ecológica à conversão de gênero para homens e mulheres, ajuda a superar a herança patriarcal das Igrejas, e amplia a categoria "cuidado", com a contribuição singular das mulheres.

PALAVRAS-CHAVE: Ecofeminismo. Ecoteologia. Hermenêutica. América Latina. Teologia feminista.

ABSTRACT: Ecofeminism is growing in importance as a significant current of thought, also of gender and socio-environmental activism. It articulates practice and

* Faculdade Jesuíta de Filosofia e Teologia, Belo Horizonte, Minas Gerais, Brasil. 
theory, criticizes patriarchalism, androcentrism and neoliberalism, and proposes a model of understanding the human being based on reciprocity, cooperation and love for the Earth. Such characteristics have not yet been widely embraced in theology. This study aims to show how ecofeminism contributes to the advancement of Latin American ecotheology, due: to its own hermeneutics, to inclusive anthropology, to language that integrates reason and emotion, to concepts and narratives, and to values of care for fragile people and the Common House. The article begins with a conceptual leveling. It presents the key points of ecofeminism and how it develops knowledge. It shows how ecofeminist theology develops a creative synthesis of conceptual elaboration, female protagonism, struggle in defense of women and the biosphere, and liberating spirituality. It concludes by presenting the various interfaces between ecofeminism and ecotheology. An ecological and feminist theology is fruitful for Christian practices and theory because it re-reads the Bible and Tradition under current categories, takes up the basic intuitions of liberation theology, associates ecological conversion with gender conversion for men and women, helps overcome the patriarchal heritage of the Churches, and expands the category of "care" with the unique contribution of women.

KEYWORDS: Ecofeminism. Ecotheology. Hermeneutics. Latin America. Feminist theology.

\section{Introdução}

$\mathrm{E}$ ra uma vez um menino. Cresceu, tornou-se adulto, mas não perdeu o coração de criança. Faz algum tempo ele estava em férias, quando leu a placa: "Hoje, desova de tartarugas marinhas". Curioso, correu até a praia. Ali contemplou uma cena inaudita: os filhotinhos de tartaruga rompiam a casca do ovo, saíam dos ninhos e se dirigiam lentamente para o mar. O acontecimento era acompanhado por um coro de crianças e de mulheres que expressavam com gritos e palmas sua emoção. Então, o adulto-menino se voltou para o que restava nos ninhos. Lá estava uma bióloga. Alguém lhe perguntou: "o que você está fazendo?" Ela cuidadosamente verificava se algum ovo poderia conter um filhote e se era necessária sua ajuda. Respondeu baixinho: "estou cuidando da vida". A frase tocou seu coração de criança. Ali começava a conversão ecológica, que não terminou ainda. Hoje esse ecoteólogo ousa pesquisar sobre o ecofeminismo, pois intui que, como aconteceu naquele entardecer, descobertas surpreendentes virão para si e seus/suas interlocutores(as).

Este artigo foi elaborado por um homem cisgênero que almeja ser aprendiz e companheiro de caminho das mulheres, na sua luta conjunta por uma sociedade que supere o patriarcalismo, o domínio despótico sobre a natureza e crie relações de reciprocidade e cuidado. Não se pretende discorrer longamente sobre a ecofeminismo, suas tendências e perspectivas, e sim mostrar como essa corrente de pensamento e de ativismo 
socioambiental das mulheres colabora efetivamente para a ecoteologia latino-americana e caribenha, levando-a a ampliar seus horizontes e a encarná-la em situações reais.

O trabalho visa mostrar a contribuição singular do ecofeminismo para a ecoteologia latino-americana. Está configurado em sete passos, após a introdução, na qual se define brevemente "feminismo", "ecofeminismo" e "teologia ecofeminista". (1) Ideias-chave da crítica deconstrutiva do ecofeminismo: a denúncia do patriarcado, a cultura androcêntrica e a dupla exploração sobre as mulheres e a natureza. (2) Os humanos, seres ecodependentes e interdependentes. Resgate feminino da categoria "cuidado". (3) A crítica ecofeminista ao neoliberalismo, em vista de um novo antropoceno. (4) O ecofeminismo: aprender a pensar e atuar em redes, conjugando práticas libertárias e reflexão acadêmica. (5) O caráter visionário da teologia ecofeminista latino-americana. (6) Elementos da epistemologia ecofeminista e sua influência na teologia, a partir de Ivone Gebara. (7) Síntese e perspectivas: interface da hermenêutica ecofeminista e de sua teologia com a ecoteologia latino-americana.

Iniciemos com uma breve elucidação acerca de "feminismo", "ecofeminismo" e "teologia ecofeminista". O primeiro termo refere-se à já secular luta das mulheres, em várias partes do mundo, para ampliar o espaço vital e assegurar sua dignidade no âmbito da sociedade civil, do trabalho, da família e do próprio corpo. Esse longo percurso, que se inicia praticamente com a reivindicação do direito de votar, se estende até os dias de hoje em tantas "bandeiras de luta" de gênero, que denunciam os mecanismos de opressão e desigualdade sobre as mulheres, numa cultura sexista, patriarcal e androcêntrica e propõem caminhos para sua superação. As mulheres se liberam da reclusão na esfera doméstica, criam novas relações no âmbito familiar e passam a atuar na esfera pública. Ganham voz e vez, apesar da violência contra as meninas e as mulheres e do persistente feminicídio.

O movimento feminista, com suas reivindicações legítimas, é significativo não somente para as mulheres, e sim para todos(as), homens e mulheres, cisgêneros ou transgêneros. Quantos preconceitos a superar, estereótipos a abandonar, atitudes e posturas de dominação a extirpar, linguagem inclusiva a adotar, sensibilidade a desenvolver! Os homens só mudaremos nossa visão de gênero se, na convivência com as mulheres, reconhecermos a sua alteridade e repaginarmos nossas representações sobre aquilo que é tipicamente masculino ou feminino.

A questão de gênero é importante em qualquer canto do mundo. "Sejamos todos feministas", anuncia a escritora nigeriana Chimamanda Ngozi Adichie. Que comecemos a planejar e sonhar um mundo diferente, de homens e mulheres mais felizes, na dinâmica de reciprocidade e não de 
dominação (Chimamanda ADICHIE, 2015ํ)! Assumir a causa feminista é fundamental para vivenciar de maneira autêntica a "amizade social" e a "fraternidade universal", propostas pelo Papa Francisco na encíclica "Fratelli Tutti" (FRANCISCO, 2020). Trata-se de uma "conversão de gênero", com muitos aspectos a desaprender e a aprender. É indispensável que as virtudes e atitudes tradicionalmente atribuídas às mulheres sejam universalizadas para todos e todas. "Movermos as águas patriarcais em todos os níveis do saber se impõe como uma exigência de justiça em relação a nós mesmas e à humanidade" (Ivone GEBARA, 1997, p. 26). A perspectiva ecofeminista nos abre um referencial de experiência amplo e inclusivo, trazendo elementos novos para o pensamento e a prática humana.

Sobre esse esteio, a teologia ecofeminista, um pensar articulado sobre a fé e a partir da fé, identifica a ligação entre as mulheres e a Terra. Aborda de forma interdependente a solução para a crise ambiental e a superação da opressão das mulheres. Reflete sobre as conexões entre tudo aquilo que está vivo, intuição já presente nos nossos povos originários, "que cultivam uma intimidade carinhosa com a Terra e seus ritmos" (Maria Clara BINGEMER, 2017, p. 17). Repensa as imagens sobre Deus, a partir das experiências das mulheres. Faz uma releitura crítica e criativa da Bíblia e da Tradição eclesial. Ensaia uma espiritualidade de inteireza, que integra razão e emoção, fala com o corpo, nutre a sintonia com Deus e a totalidade da criação.

\section{Ecofeminismo: ativismo e hermenêutica inclusiva}

Nascido nos anos 70, o ecofeminismo surge como um espaço comum que congrega as reivindicações das mulheres com as metas do movimento ecológico. O termo "ecofeminismo" foi cunhado em 1974 pela ativista Françoise D'Eaubonne, que publicou na ocasião o livro "Le feminisme ou la mort" (O feminismo ou a morte). Ela faz uma síntese crítica da ecologia política de Serge Moscovici com o feminismo de Simone De Beauvoir. "Ambos criticam a ideia de natureza, mas o primeiro para torná-la o princípio virtuoso necessário à sociedade, a segunda para torná-la o princípio a ser superado e transcendido" (Anne-Line GANDON, 2009, p. 8). Constata-se que ativismo de base do movimento ecológico no mundo é majoritariamente feminino. Paradoxalmente, predominam ainda as lideranças masculinas. Então, as mulheres se mobilizam para assegurar uma equidade de gênero também

\footnotetext{
${ }^{1}$ Algo caro às mulheres consiste em reconhecer seus nomes, como parte constitutiva de um tecido comunitário. Infelizmente a forma padronizada de citações no corpo dos artigos científicos concede exclusividade ao sobrenome, colocando na sombra o nome das autoras. Dessa forma, ignora a contribuição específica das mulheres. Por isso, nesse artigo explicitaremos o nome das autoras, antepondo-os aos sobrenomes, mesmo que tal procedimento não seja consoante com os cânones da academia.
} 
no campo dos movimentos socioambientais e do pensamento ecológico (Anne-Line GANDON, 2009, p. 5-6).

Três ideias chaves são comuns nos vários grupos ecofeministas: (a) há uma conexão estreita entre a opressão sobre as mulheres e a dominação e exploração da natureza; (b) segundo a visão patriarcal, as mulheres estão mais perto da natureza e os homens, da cultura, e isso justificaria a inferioridade delas; (c) como ambas as dominações se dão em paralelo, as mulheres lutam não somente por sua autonomia, como também para curar a natureza alienada. Os movimentos feministas e ambientais são a favor de sistemas igualitários e não hierárquicos. $\mathrm{O}$ feminismo ecológico convoca homens e mulheres a reconceitualizar-se a si mesmos(as) e às relações interpessoais e com o mundo não humano, na ótica da reciprocidade, e não da competição.

A análise emancipatória ecofeminista identifica o núcleo da opressão no patriarcado. Esse é compreendido como um sistema de organização social em que as posições-chave de poder (político, econômico, religioso e militar) estão, exclusiva ou majoritariamente, nas mãos dos homens. Sendo um sistema de dominação masculina, profundamente enraizado na cultura, dita normas e condutas para mulheres e homens. Essas parecem naturais e inquestionáveis, tanto no campo das microrrelações (como na família), quanto nas estruturas sociais e na ideologia dominante. Enquanto que nas sociedades antigas predominava o patriarcalismo de coerção, hoje no ocidente vigoram patriarcados de consentimento. $\mathrm{O}$ patriarcado é metaestável, pois suas formas se adaptam aos diferentes tipos históricos de organização econômica e social, mas preservam em maior ou menor grau seu caráter de sistema de exercício de poder e de distribuição de reconhecimento entre homens e mulheres (Alicia PULEO, 2006). O patriarcalismo é um marco conceitual opressivo, que explica, justifica e mantém relações de dominação e subordinação contínua e sistemática.

A intuição básica do ecofeminismo é que no ocidente e nas culturas patriarcais há uma conexão profunda entre a dominação das mulheres e da natureza. Tal sujeição se estabelece em primeiro lugar no nível cultural-simbólico e se sustenta em estruturas socioeconômicas. Assim, a colonização do corpo e do trabalho das mulheres está interligada com a exploração da terra, da água e dos animais (Rosemary RUETHER, 1996, p. 130). O antropocentrismo da modernidade e o androcentrismo (que considera o varão como a única representação completa do humano) formam parte da epistemologia patriarcal, que dá suporte a esses modelos de pensamento configurados de uma maneira dicotômica e hierárquica. $\mathrm{O}$ ecofeminismo contribui para mostrar que a crise de cuidados e a crise socioecológica global se correlacionam em suas manifestações. E, de outro lado, aumentar a sensibilidade ecológica é fundamental para a continuidade da vocação de sororidade internacional feminista (Alicia PULEO, 2011, p. 20) 
Devido às suas características orgânicas, o corpo das mulheres é mais vulnerável à poluição ambiental. Por exemplo, o câncer de mama devido sobretudo à contaminação com os xenoestrógenos dos pesticidas organoclorados, as dioxinas dos incineradores, as resinas sintéticas, as pinturas, os produtos de limpeza, os envoltórios de plástico e outros objetos de uso cotidiano. Sem demonizar os produtos químicos e a tecnociência, é preciso desvendar os seus limites. A crítica ecofeminista ajuda as mulheres a cuidar do corpo, frente a uma confiança excessiva na tecnociência que as leva "a submeter-se de forma crescente a mandatos sociais colonizadores e agressivos" (Alicia PULEO, 2011, p. 13-14), sem se perguntar sobre os riscos para sua saúde.

Simultaneamente prático e teórico, o ecofeminismo analisa a cotidianidade das relações de poder entre os gêneros, em âmbito interpessoal e social, e propõe alternativas viáveis. Critica a visão ingênua de "meio ambiente", como se esse fosse um simples cenário das atividades humanas. Prefere o termo "natureza" ou outro correlato, pois reconhece o valor inerente dos outros seres e dos ecossistemas em conjunto, numa relação de parentesco e semelhança. Assume uma atitude empática em relação à comunidade de vida do planeta, a biosfera. Gesta um modelo de compreensão amplo e complexo, em estreita relação com o paradigma ecológico. Ecologia e feminismo se completam, mantendo a especificidade de cada um.

Ao compartilhar e intercambiar sua potência conceitual e política, feminismo e ecologismo ( ${ }^{*}$ movimento ecológico) conseguem iluminar melhor certos aspectos dos problemas que cada um enfrenta e, dessa maneira, ganhar em profundidade e eficácia (Alicia PULEO, 2011, p. 8).

O ecofeminismo fornece chaves "para repensar as contradições atuais, reverter os imaginários dominantes e propor novas formas de relação com a natureza e entre as pessoas" (Andrea DÍAZ ESTÉVEZ, 2019). Nessa mesma linha, afirma a filósofa norte-americana Karen Warren:

A promessa e o poder de feminismo ecológico radica no fato de proporcionar um marco único para conceber de maneira inovadora (novedosa) o feminismo e desenvolver uma ética ambiental que leve a sério as conexões existentes entre a dominação das mulheres e a dominação da natureza (Karen WARREN, 2004, p. 233).

As ecofeministas reconhecem as diferenças (biológicas e/ou culturais) entre homens e mulheres, sem que isso alimente a dominação. Defendem que a erradicação da opressão sexista exige suprimir outras formas de opressão, como a dominação de classe, o racismo, o heterossexismo, o etarismo, e outros "ismos", pois há conexões entre elas. Assim, o feminismo necessita ser ecológico, pois as questões socioambientais são também "assuntos de mulher", de sua existência pessoal e coletiva. E de outro lado, uma ética ambiental responsável tem que abraçar o feminismo, para que a diferença, tão perceptível na questão de gênero, não engendre a dominação. Se isso 
não acontecer, a fonte da subordinação das mulheres e da natureza se perpetuará (Karen WARREN, 2004, p. 234-235, 241-243, 251, 257).

O ecofeminismo crítico afirma que a categoria "mulher" não deve redundar em generalizações. Mulheres brancas e ricas do $1^{\underline{0}}$ mundo vivem em situação muito diferente de mulheres pobres, indígenas e afrodescendentes do outro lado do planeta. O ecofeminismo estabelece conexões concretas com as mulheres que estão na base do sistema socioeconômico. Na medida em que ligam suas histórias e suas lutas com as mulheres que estão na parte inferior dos atuais sistemas de poder e de lucro, vislumbram-se uma teologia e uma ética ecofeminista significativas (Rosemary R. RUETHER, 1996, p. 139). No dizer de Alicia PULEO: "Se em nome da justiça desejamos que nossa qualidade de vida se estenda a toda a humanidade, essa deve mudar e fazer-se sustentável" (2002b).

\section{Ecodependência e Interdependência: para uma cultura do cuidado}

A edificação de uma cultura da emancipação e participação requer desconstruir alguns mitos da visão dicotômico da "ideologia do domínio", ainda vigente (Yayo HERRERO 2011, 2013), O primeiro mito, segundo a autora, consiste na concepção do homem como dono da natureza. Concebendo-a como uma máquina, ela é despojada de seu caráter divino, "impredizível", inabarcável e misterioso. Ora, a natureza é um sistema complexo, no qual não existem somente relações de causa-efeito, mas também de realimentação e sinergia. O segundo mito diz respeito à "deslocalização do ser", como consequência da relação dicotômica entre a mente e o corpo. Segundo o racionalismo, o que importa é a mente e sua capacidade de pensar, de raciocinar. Ora, ao situar o feminino, dicotomicamente separado do masculino, no mesmo lado que a natureza e o corpo, se justificaria submeter e explorar as mulheres.

O pensamento ocidental dual interpreta o mundo organizando-o em uma série de pares opostos que separam e dividem a realidade: natureza $x$ cultura, razão x emoção, ciência e saberes tradicionais. Mas não considera as relações mútuas e a complementaridade entre eles. As dicotomias apresentam um caráter hierárquico. Uma das posições é tida como superior à outra. A visão feminista alvitra que tais pares devem se associar uns aos outros para além da forma binária.

Yayo HERRERO, baseada no pensamento de José Manuel NAREDO (2006) mostra que a economia de mercado se transformou numa "nova religião civil", edificada sobre crenças de ficção, num "fundamentalismo econômico". A primeira ficção consiste em desvincular a produção da vida e 
reduzir o valor ao que é exclusivamente monetário. Reputa-se que algo tem valor se cumpre três características: é expresso em moeda, pode ser apropriado, comprado ou vendido por alguém, e tenha recebido alguma transformação ("foi produzido"). A redução de noção de valor à grandeza do preço conduz à crença que terra e trabalho possam ser substituídos pelo capital. A terceira ficção do fundamentalismo econômico reside em acreditar que "produzir mais é sempre melhor". Qualquer crescimento econômico, independente da natureza da atividade que a sustenta, seria positivo em si mesmo e garantiria o bem-estar social. Não se cogita que processos produtivos consomem energia, geram resíduos, podem esgotar recursos finitos e explorar trabalhadores e trabalhadoras. Ignoram-se as externalidades e os efeitos negativos colaterais.

A quarta ficção consiste em conceber que "trabalho é somente o que se faz em troca do salário". Com isso, todas as funções realizadas pelas mulheres no espaço da produção doméstica, que asseguram a reprodução e cuidado dos corpos humanos foram desconsideradas. E as pessoas excluídas do trabalho remunerado não tem direitos sociais por si mesmas (Yayo HERRERO, 2013, p. 290-297). Ora, o ecofeminismo repagina o conceito de trabalho, rompendo a dicotomia entre a esfera pública, a da produção, e aquela doméstica, da reprodução. Trabalho se compreende, em sentido amplo, como "prática de criação e recriação da vida e das relações humanas" (Anna BOSCH et al., 2003), incluindo fatores materiais e simbólicos.

A cultura capitalista, na sua luta contra os limites físicos humanos, despreza a velhice, a doença e a morte. Dá as costas à vulnerabilidade do corpo, construindo uma ilusão delirante de imortalidade. Em contraposição, as ecofeministas valorizam o trabalho daqueles(as) que se ocupam em manter e cuidar dos corpos vulneráveis e retiram as mulheres da invisibilidade (Yayo HERRERO, 2013, p. 284-289). Todos(as) necessitamos de cuidados, configurados segundo o momento do nosso ciclo vital. Não somente aqueles físicos e econômicos, mas também os emocionais, que perpassam toda a existência.

Enquanto humanos, somos corpo, em suas diferentes dimensões: "materialidade, aparência, estética, gestualidade, movimento, sensorialidade, emoção, percepção, intuição e cognição" (Yayo HERRERO, 2013, p. 289). Nele se articulam o físico, o simbólico e o sociológico. Assumir a finitude do corpo, sua vulnerabilidade e suas necessidades contribui para assumir o caráter interdependente de nossa espécie, situando aí a reciprocidade, a cooperação, a criação e manutenção de vínculos saudáveis. Com isso, se vence a ilusão antropocêntrica e androcêntrica de independência e autonomia. Tal avanço impacta também na ecologia, pois tanto o corpo humano quanto os ecossistemas são finitos, limitados e estão sujeitos à degradação.

O cuidado foi muitas vezes desvalorizado e considerado uma obrigação para as mulheres. Elas são as encarregadas de praticamente todas as tarefas de cuidado indispensáveis para sustentar a vida humana, tais como: cuidar 
das pessoas idosas e doentes, a criação dos filhos, a preparação da comida, a limpeza da casa. Ora, a mulher não é "naturalmente" cuidadora. Mas as tarefas que ela historicamente assumiu (e assume ainda) a tornaram mais propensa a desenvolver atitudes empáticas para os mais vulneráveis. Então, devemos "revalorizar e universalizar essa atitude empática, esse cuidado do vulnerável, vinculando-o também aos varões, e aplicando-o aos demais seres vivos e aos ecossistemas" (Andrea DÍAZ ESTÉVEZ, 2019)

Algumas ecofeministas sustentam que é necessário "renaturalizar" o varão. Isso significa readequar a organização política, relacional, doméstica e econômica às condições da vida humana para homens e mulheres. Ao mesmo tempo, se constrói uma nova cultura, que visibiliza a ecodependência e a interdependência para mulheres e homens. Experienciar a interdependência humana é essencial para a valorização da vida e a reconstrução da sociedade. Trata-se de "mudar os óculos" para compreender e atuar em vista de um mundo sustentável (Yayo HERRERO et al., 2011). Isso implica também modificar o ritmo de vida pessoal e institucional.

Compreender a vida significa também aceitar seu ritmo. O crescimento lento, as mudanças pequenas, os matizes, nos aproximam mais dos modos de vida sustentáveis que os ritmos rápidos e os fortes contrastes, comuns no nosso entorno urbano e virtual (Yayo HERRERO, 2013, p. 302).

Frente aos vícios da modernidade antropocêntrica, ecofeministas sustentam que os humanos somos ecodependentes e interdependentes. Precisamos da natureza para viver e sobreviver, como também necessitamos dos outros seres humanos, que dedicam tempo e energia para cuidar de nossos corpos, especialmente na infância, na velhice e na doença. Durante toda a existência estabelecemos relações interdependentes com outros homens e mulheres. Do ponto de vista filosófico e antropológico, o feminismo permite reconhecer, situar e compreender melhor a beleza e fragilidade da espécie humana. Mostra como é funesta a divisão estrita que o ocidente estabeleceu entre natureza e cultura, corpo e razão, mulher e homem. Denuncia a perspectiva reducionista que não dá conta das totalidades, simplifica a complexidade e invisibiliza a importância central dos vínculos. A revisão dos esquemas mentais e das representações antropocêntricas e patriarcais nos leva desenhar transições para outras formas de viver e conviver, "reconstruir o que se perdeu e inventar o que nunca aconteceu" (Yayo HERRERO, 2013, p. 280-282).

Além de utilizar conceitos precisos e significativos, o ecofeminismo expressa convicções, sentimentos e esperanças através de analogias, símbolos, literatura, poesia e narrações da experiência em primeira pessoa. $\mathrm{Na}$ ética, a narrativa é um reflexo das experiências sentidas e vividas. Como também uma forma de pensar sobre elas, levando em conta as realidades históricas, materiais e sociais na qual os sujeitos morais estão inseridos. E isso tem relevância para a argumentação (Karen WARREN, 2004, p. 247). 
Segundo a autora, especialista em ética filosófica, o enfoque ecofeminista leva "a uma mudança de atitude, de uma percepção arrogante a uma percepção amorosa do mundo não humano" (Karen WARREN, 2004, p. 249). Tal percepção amorosa permite acolher que os seres não humanos, diferentes de nós, são "outros" que merecem nossa consideração e reconhecimento ético. Os humanos somos ao mesmo tempo membros de uma comunidade ecológica, e distintos dela. Não se pretende uma eliminação da diferença, e sim um reconhecimento respeitoso.

A ética ecofeminista é contextualizada e comunitária. Como em um mosaico, o que importa não é ter uma imagem baseada em uma só voz, mas um desenho que surge de vozes diferentes de muitas mulheres situadas em diferentes circunstâncias. Caracteriza-se assim como pluralista, processual, mutável e inclusiva (Karen WARREN, 2004, p. 252, 253). Ela outorga relevância central a alguns valores que foram desdenhados na ética vigente, como o cuidado, a amizade, a confiança e a reciprocidade.

\section{Neoliberalismo e as mulheres: denúncia e alternativas no antropoceno}

Contemporaneamente, o ecofeminismo analisa as relações entre a violência dos sistemas econômicos injustos e não sustentáveis e a crescente violência - simbólica ou brutal - contra as mulheres. A situação das mulheres piorou consideravelmente com a ascensão do neoliberalismo, a face atual do "patriarcado capitalista" (Vandana SHIVA; Maria MIES, 2016, p. 1719). Nesse sistema, a economia é reduzida ao mercado. Então, denuncia a ecofeminista indiana,

(..) o limite da produção ignora o valor econômico de duas economias vitais que são necessárias para a sobrevivência humana e ecológica: a economia da natureza e a economia de subsistência. Nessas economias (..) a moeda em circulação são os processos que dão vida, não o dinheiro nem o preço do mercado (Vandana SHIVA; Maria MIES, 2016, p. 20).

O modelo de patriarcado capitalista da economia neoliberal afasta as mulheres, especialmente as do terceiro mundo, dos seus meios de vida e dos recursos que necessitam para existir, como a terra, as florestas, a água, as sementes e a biodiversidade. Os poderosos continuam investindo no crescimento ilimitado, em um planeta limitado, porque se apropriam dos recursos dos vulneráveis.

Vandana Shiva enfatiza: a violação da Terra e a violação das mulheres estão estreitamente relacionadas, tanto do ponto de vista metafórico, pelas cosmovisões que se impõem, como material, ao condicionar a sua vida cotidiana. Além disso, as reformas econômicas promovidas na atual onda 
neoliberal no mundo conduzem à subversão da democracia e à privatização do governo. Os políticos se colocam a serviço do capital, ignorando as demandas das pessoas que supostamente representam (Vandna SHIVA; Maria MIES, 2016, p. 20). A classe política alienada, com medo dos cidadãos, passa a utilizar a violência policial e reprime os protestos pacíficos. As forças de segurança deixam de lado sua obrigação de proteger as mulheres e os mais frágeis. Um Estado corporativo privatizado se converte então num "Estado policial". A esse panorama se agrega a colonização do mundo pelas transnacionais da biotecnologia, um fenômeno crescente, silencioso e perigoso (Alicia PULEO, 2011, p. 10). O modelo econômico determinado pelo patriarcado capitalista converte tudo em mercadoria, para ser colocado à venda, inclusive as mulheres. Tal economia da mercantilização cria uma cultura da mercantilização, "na qual tudo tem um preço e nada tem valor" (Vandana SHIVA; Maria MIES, 2016, p. 22).

A análise arguta de Vandana Shiva converge com a visão crítica que denuncia o crescimento desmedido do capital financeiro, estreitamente relacionado com o neoliberalismo. O economista brasileiro Ladislau Dowbor o denomina "a era do capital improdutivo" (DOWBOR, 2017). Um bilionário que aplica o seu dinheiro no mercado financeiro ganha sem precisar produzir nada. A cada dia a maior parte de sua riqueza é reaplicada, gerando um enriquecimento improdutivo que gradualmente multiplica bilionários e trava a economia. Mesmo nas crises econômicas, no cassino financeiro mundial, o $1 \%$ dos mais ricos do planeta se apropriam de mais riqueza do que os $99 \%$ seguintes. A crescente aplicação no mercado financeiro contribui para a acumulação de riqueza à custa dos processos produtivos. Isso implica, em outras coisas, a queda de geração de emprego e renda (DOWBOR, 2019).

Como a maioria da população do Brasil está concentrada nas cidades e o agronegócio se transformou em motor da economia de exportação, associado a uma propaganda massiva e sedutora de "agro é pop, agro é tudo", não nos damos conta da gravidade do capitalismo no campo e das ameaças reais à segurança alimentar. A denúncia de Vandana Shiva serve como um sinal de alerta para nossas consciências adormecidas.

Uma economia baseada na desregulação do comércio e na privatização e a mercantilização das sementes e alimentos, da terra e água, das mulheres e crianças, degrada os valores sociais, reforça o patriarcado e intensifica a violência contra as mulheres (Vandana SHIVA; Maria MIES, 2016, p. 23).

O antropoceno destrutivo expressa a arrogância, a vaidade e a cegueira dos humanos, que se consideram senhores, conquistadores e proprietários dos recursos da terra. Ele se manifesta em cultura da dominação, violência sob várias formas e irresponsabilidade ecológica. Em contrapartida, o ecofeminismo propugna uma mudança na economia, na cultura e na visão das pessoas. É necessário superar o paradigma do patriarcado capitalista, sus- 
tentado numa cosmovisão mecanicista, na economia competitiva, industrial e centrada no capital. Vandana Shiva expressa a visão das ecofeministas, semelhante a outras pessoas e organizações ecológicas. Essas se consideram membros da família Terra, responsáveis pelas outras espécies e pela vida no planeta em toda sua diversidade, desde os micro-organismos até os grandes mamíferos. Pautam-se pelo imperativo de viver, produzir e consumir dentro dos limites ecológicos do nosso planeta. Valorizam mais a cooperação do que a competição.

Coloca-se então a ingente tarefa de construir o antropoceno criativo da democracia na Terra. Isso significa trabalhar conjuntamente como cocriadores(as) e correprodutores(as), utilizando a inteligência e a sensibilidade para conservar e curar. Conectar-se com a Terra, sua diversidade e seus processos vivos (Vandana SHIVA; Maria MIES, 2016, p. 27-28). É possível sonhar e investir numa nova sociedade? Sim! É verdade que há um enorme desnível entre as mobilizações sociais e a brutalidade da ofensiva neoliberal. Mas a humanidade já dispõe de propostas e diretrizes, incompletas e provisórias, para realizar transições socioecológicas em direção a outro modelo de economia e organização social (Yayo HERRERO, 2013, p. 302). As mulheres não são somente vítimas desse sistema perverso. Elas sobressaem como sujeitos ativos no cuidado com a Casa Comum e na edificação de uma nova cultura com respeito à natureza, junto com pessoas de outros gêneros e diversos grupos sociais. As ecofeministas contribuem de forma singular para uma "cultura ecológica da igualdade" (Alicia PULEO, 2011, p. 16).

\section{Aprender a pensar e atuar em múltiplas redes}

A perspectiva ecofeminista ensaia uma cosmologia e antropologia que postula: a vida se mantém por meio da cooperação e do cuidado mútuo. Tal visão intenta ser holística, englobando todos os aspectos da vida. "A proposta para um futuro mais justo passa por esse cuidado, entendido como preocupação, atenção, proteção e como uma tarefa essencialmente coletiva" (Andrea DÍAZ ESTÉVEZ, 2019, grifo nosso).

Mulheres em várias partes do mundo se empenham em causas que condensam, simultaneamente, questões de gênero, sociais, étnicas e ecológicas. Criam redes para compartilhar métodos eficazes de protesto e de alternativas sustentável e inclusivas (Vandana SHIVA; Maraia MIES, 2016, p. 31). Elas criticam a ilusão da tecnociência, que associada ao capital, propõe soluções estupendas para a humanidade, mas produzem mais problemas. Basta pensar nos transgênicos e nos desastres em usinas nucleares. Os "pais da destruição" são incapazes de aprender com os fracassos. Tão obstinados com suas conquistas unidimensionais, têm memória fraca. "A destruição da natureza, as novas armas, a engenharia genética, a agricul- 
tura moderna e outras invenções são "ocorrências", ideias dessa ciência reducionista, supostamente carente de valores" (Vandana SHIVA; Maria MIES, 2016, p. 30).

O ativismo ecofeminista, que atua junto com outras organizações da sociedade civil, é uma grande escola de múltiplas aprendizagens. Ele assume faces originais, de acordo com o ambiente vital onde se enraíza e se desenvolve. No continente latino-americano, ele se associa às lutas das mulheres indígenas e dos povos originários, das mulheres afrodescendentes e dos grupos quilombolas, das comunidades que resistem às investidas da mineração, nas organizações em defesa da dignidade do corpo das mulheres, e nas que enfrentam o tráfico humano. A lista acima, meramente ilustrativa, na prática é muito mais ampla. O ecofeminismo não é um movimento reducionista ou meramente corporativo. Nele ressoam problemas, sonhos, alternativas e perspectivas que tocam a humanidade e o planeta, compreendidos e vivenciados a partir da ótica das mulheres. E aí reside um de seus componentes mais significativos e originais.

O ecofeminismo articula práticas e saberes, ações transformadoras e fértil produção acadêmica. Vivencia um adágio clássico da Teologia da libertação latino-americana: "o lugar social condiciona o lugar hermenêutico". Para compreender por dentro o que é uma situação social insuportável, é preciso entrar nela e buscar mudá-la. Assim, “a experiência e a luta vão na frente do estudo teórico" (Vandana SHIVA; Maria MIES, 2016, p. 32).

Como o feminismo consiste em teoria e prática ligadas às experiências vitais das mulheres, que são múltiplas, sua pluralidade é evidente. Elizabeth SCHÜSSLER FIORENZA (2009, p. 76-80) identifica 15 abordagens diferentes do feminismo, que se combinam "para atacar as muitas cabeças do monstro do Kyriarcado". Ideias e práticas ecofeministas se consubstanciam em várias correntes, com algumas figuras de destaque, como: a cultural/espiritual (Rosemary Radford Ruether, Vandana Shiva), a Social ou "construtivista" (Val Plumwood, Maria Mies, Yayo Herrero, Karen Warren) e a crítica (Alicia Puleo) (Manuela TAVARES, 2014). A própria Alicia Puleo distingue o ecofeminismo essencialista (existiriam características femininas universais, como o cuidado), o construtivista (as identidades de homem-mulher seriam construções sociais e históricas), o espiritualista, e o ilustrado ou crítico que ela assume como sua posição (Alicia PULEO, 2002a, 2010, 2016; Andrea DIÁZ ESTÉVEZ, 2019). Pleiteia-se que as promessas da ilustração (igualdade, fraternidade, autonomia, pensamento crítico e autocrítico) se efetivem para as mulheres e com elas, rejeitando o androcentrismo e se engajando por um novo modelo de sociedade.

O ecofeminismo latino-americano e caribenho, que elabora seu saber em estreita relação com o mundo dos pobres, a diversidade étnica e cultural e a pluralidade religiosa, é por vezes identificado como "ecofeminismo 
espiritualista" (Alicia PULEO, 2002a, 2002b), em parte devido a sua ligação originária com a Teologia da libertação e com as religiões dos povos originários. Acrescenta-se o fato que o ecofeminismo do nosso continente tem assumido a linha da decolonialidade (Eloísa BUARQUE DE HOLANDA, 2020). Enfatiza não tanto a contribuição da ilustração (aufklärung) europeia para a evolução da humanidade, mas, sim, o seu reverso. Ou seja, as estruturas de dominação que influenciam até hoje nossos povos, subalternizando-os.

A antropologia do ecofeminismo descontrói o imaginário antropocêntrico do ser humano como autônomo, racional e todo-poderoso. Ela nos vê como parte da terra, seres sociais, interdependentes, ecodependentes, incompletos, finitos, vulneráveis, necessitados uns dos outros(as) e da natureza. Trate-se de socializar para todos e todas aquilo que se atribuía, de forma impositiva e unilateral, somente às mulheres: o cuidado recíproco e coletivo. Tal postura se revela, então, como primeiro passo para uma sociedade antipatriarcal e anticapitalista. Seria um dos eixos centrais para impulsionar uma cultura sustentável.

Embora tenha avançado muito na metodologia e na linguagem, ecofeministas reconhecem que há um gap entre seu discurso programático e a situação existencial de seus destinatários(as) e interlocutores(as). Por exemplo, a distância entre o discurso político de natureza analítica e crítica, e a linguagem das emoções.

Os movimentos sociais temos uma importante riqueza conceitual e nos movemos com soltura no campo do racional, mas temos uma miséria simbólica e conectamos mal com as emoções. Não há revolução sem paixão, sem amor pela vida e pelas pessoas (Yayo HERRERO, 2013, p. 303-304).

\section{Teologia ecofeminista na América Latina e Caribe: algumas pinceladas}

A teologia feminista é reflexão sobre a fé ou a partir da fé em Jesus Cristo, realizada sob a ótica de gênero e da reciprocidade. Ela surge "como uma mudança radical do modo como refletimos os dados da revelação e os textos das Escrituras, e também como pensamos o mundo e suas relações entre pessoas, natureza e divindade" (Maria Clara BINGEMER, 2017, p. 79). Empenha-se em repensar toda a teologia, como também a cosmologia e a antropologia, que durante séculos sofreu forte influência patriarcal. $\mathrm{O}$ salto qualitativo da teologia feminista consiste em relacionar o discurso sobre Deus com a experiência de vida das mulheres. Expande-se a própria imagem de Deus. Essa corrente teológica não só reflete a partir das mulheres, mas também propõe uma hermenêutica que rompe 
as amarras patriarcais e estimula a humanidade, homens e mulheres, a viver a fraternidade e a sororidade.

Sem pretender localizar com precisão a origem da teologia ecofeminista latino-americana, tomemos a título de exemplo uma publicação paradigmática: o fascículo 1 do coletivo "Con-spirando", de teólogas, pastoralistas e militantes ecofeministas do Chile, de março de 1992. Conforme anunciado no subtítulo, Con-spirando é uma revista latino-americana de "ecofeminismo, espiritualidade e teologia". A analogia de respirar juntas "nos traz imagens do planeta como um grande pulmão de vida" (Colectivo editorial, Con-spirando 1, 1992, p. 1). A combinação de causa de gênero, lutas sociais, reflexão teológica e mística marca o percurso do ecofeminismo crente no nosso continente. E constitui, ao seu modo, uma chave fundamental para compreender e cultivar a ecologia integral.

Desde o início, as publicações de Con-spirando incluem poesia, testemunhos, ritos e resenhas. A somatória de conceitos, analogias, apresentações pictográficas e poesia evidencia um caminho novo de elaboração de discurso, uma forma de reunir dimensões da expressão humana que a ciência moderna fragmentou e hierarquizou. A grande parte dos desenhos do número inaugural da revista provém da arte mapuche, refletindo o compromisso de valorizar as raízes indígenas. No que diz respeito à redação, "damos preferência às formas femininas para contrapor-se ao peso de uma linguagem tão excludente que é o normativo em toda América Latina" (Colectivo editorial, Conspirando 1, 1992, p. 1).

O grupo do Chile que lançou Con-spirando teve contato com mulheres na Argentina, no Brasil, Peru, México, Uruguai e Venezuela. Elas enfatizam a gravidade e a urgência da questão ecológica. É necessário mudar as formas de relacionamento, substituir a dominação pela colaboração e o respeito, a verticalidade pela horizontalidade, entre homens e mulheres e dos seres humanos com a natureza, pois está em jogo a continuidade da vida no nosso planeta. Além disso, a perspectiva feminista se edifica a partir de e com as diversidades de classe, etnia, idade e cultura (Elena AGUILLA, 1992, p. 3, 5).

Há um liame que une o movimento ecofeminista e a eclosão de uma espiritualidade própria, traduzida em diferentes tradições religiosas. Esse "reconhece nosso enraizamento na natureza, nossa interconexão com todas as formas de vida [..], a dimensão sagrada com todo o criado, tal como faziam nossas antepassadas. Olha a criação com reverência, gratuidade e compaixão" (Rosa TRAPASSO, 1992, p. 7, 8).

Vem à tona a originalidade da experiência espiritual das mulheres, que dizem: "sentimos a Deus de outra maneira". Descobrem-se traços de Deus, que a Tradição cristã ignorou. Gestar, dar vida, assumir a responsabilidade pela criação dos filhos (muitas vezes sozinhas, pois o homem se ausenta), 
educar, atuar e esperar o crescimento com paciência, observar as mudanças no outro(a) e na natureza. Tudo isso desencarcera a visão bíblica de Deus como misericórdia materna, que sente compaixão por seu povo. Ele(a) é criador(a), companheiro(a) e educador(a).

Já nas suas origens a teologia ecofeminista latino-americana percebeu a íntima relação entre a busca de identidade das mulheres, seu engajamento coletivo e o cultivo da espiritualidade. Essa implica também novas práticas com respeito ao culto, à devoção e ao rito. Critica-se o formalismo religioso, a rigidez, o esquema hierárquico e a linguagem sexista presente nas palavras e nos gestos das celebrações religiosas oficiais das igrejas.

Ao mesmo tempo, as mulheres criam e redescobrem distintas formas, gestos, ritos e símbolos para nutrir e expressar sua fé. Isso implica o envolvimento do corpo com gestos, cantos e danças. Recuperam-se símbolos da natureza, como a terra, a água, o vento e o fogo, que as conectam com as tradições dos povos originários e da espiritualidade judaico-cristã. E se criam outros. As mulheres, quando se juntam para realizar o rito, experimentam que se sentem parte e da natureza, em relação com a Transcendência; encontram-se com outras semelhantes e se recompõe em uma ação co-participativa; expressam seus sentimentos e emoções, comunicam-se com símbolos que reconstroem significados portadores de valores e anelos (Josefina HURTADO, 1992, p. 37).

Foge do foco desse artigo apresentar um panorama dos principais temas e das autoras mais significativas de teologia feminista no nosso continente. Concentramo-nos no ecofeminismo, enquanto ativismo e corrente de pensamento, e sua correspondente proposta epistemológica. Mas vale destacar, sumariamente, alguns aspectos da contribuição singular da teologia feminista. Através de distintas metodologias, hermenêuticas e contextos, ela empreende a enorme tarefa de reler toda a teologia, como fez a teologia da libertação. Se tomamos a revisão e a ampliação de pensar a fé a partir da antropologia unificadora, destacam-se: a linguagem sobre Deus Trindade, a antropologia teológica, a eclesiologia, os ministérios, a liturgia e o culto, a mariologia, a ética sexual e social (María Teresa SANTISO, 1995, p. 71-79).

A teologia feminista privilegia o método indutivo, pois parte da experiência. A finalidade de seu trabalho é muito mais "teologizar" do que construir um sistema teológico, que tende a ser rígido com o tempo. Ela visa desencadear um processo dialético de ação e reflexão, visando avançar no pensamento e na prática e colocar novas perguntas (María Teresa SANTISO, 1995, p. 69).

Atualmente a teologia feminista e seu acento ecológico têm se expandido de maneira admirável. Cada vez mais mulheres estudam e produzem teologia. Embora ainda estejamos longe da equidade de gênero, cresce o 
número de professoras, pesquisadoras e pastoralistas em instituições de ensino, pastorais e organismos eclesiais. Mulheres ocupam espaço nas revistas de teologia e ciências da religião, escrevendo artigos e coordenando sua edição. A equidade nas instituições e ensino superior ainda é uma conquista e se realizar (María LÓPEZ BELLOSO, Mará SILVESTRE CABRERA e Irene GARCÍA MUÑOZ, 2021).

Destaca-se entre as produções feministas a coleção "Mujeres haciendo teologías", coordenada por Virgínia AZCUY, Gabriela DI RENZO e Celina MENDONZA, abarcando teólogas da América Latina, Caribe e Estados Unidos. O volume 1 é um dicionário de obras de autoras (2007) que reúne recensões de obras individuais e compiladas, livros e artigos teológicos. O volume 2 compreende uma antologia das autoras (2008), na qual se apresenta um resumo de artigos com um breve comentário. Dentre elas, relembramos aqui os nomes latino-americanos de Barbara Andrade, María Pilar Aquino, Virgínia Azcuy, Maria Clara Bingemer, Tereza Cavalcanti, Ivone Gebara, Maria Teresa Santiso, Antonieta Potente, Mary Judith Ress, Elza Tamez, Ana Maria Tepedino, Olga Vélez Caro, Tânia Sampaio, María del Socorro Albán e Lúcia Weiler. E dentre as teólogas dos Estados Unidos, Joan Chittister, Mary Daly, Mary Hunt, Elizabeth Johnson, Sallie McFague, Rosemary Ruether e Elizabeth S. Fiorenza. Já o volume 3 consiste num estudo de autoras (2009), no qual teólogas refletem sobre o pensamento de suas companheiras. O conjunto das três obras demonstra a consistência e originalidade das teólogas e de sua produção.

Vale também fazer referência à contribuição crescente e significativa de ecoteólogas na RIBLA (Revista de Interpretação Bíblica Latino-americana), na Voices (revista internacional de teólogos/as do terceiro mundo) e em periódicos especializados de Teologia e Ciências da Religião no Brasil, como Perspectiva Teológica, Atualidade Teológica, Horizonte, Pistis e Práxis, Estudos Teológicos, Caminhos, Fronteiras, e Revista de Cultura Teológica.

\section{Ecofeminismo e teologia. Breves considerações epistemológicas}

Em "Teologia ecofeminista: Ensaio para repensar o conhecimento e a religião" (1997), Ivone Gebara delineia a epistemologia dessa corrente teológica. Seguindo livremente as inspirações da pedagogia libertadora de Paulo Freire, nossa autora mostra que o ecofeminismo ajuda a descobrir os perversos mecanismos de dominação sobre a natureza e as mulheres e introduz novas formas de pensar em vista da ecojustiça. As questões éticas estão no bojo das epistemológicas, interligando conhecimento e ação, de forma libertadora. 
A epistemologia ecofeminista não é uma novidade que se impõe à primeira abordagem, nem algo pronto para ser adquirido como um novo livro; é uma atitude, uma busca de sabedoria, uma convicção que se desenvolve em conexão com o conjunto de todos os seres vivos (Ivone GEBARA, 1997, p. 31).

Em que sentido dizemos que grande parte das epistemologias geradas no ocidente são de base antropocêntrica e androcêntrica? Não que tenham sido falsas ou eticamente maldosas, mas, sim, unilaterais. Elas se referem particularmente às experiências de uma parte da humanidade, mas as apresentam como se fossem a todos os humanos. Quando se falava em Saber com alto grau de conhecimento, profundidade e extensão, o padrão era aquele desenvolvido e divulgado pelos homens. "Pobres e mulheres eram associados a níveis mais baixos de abstração, de ciência e sabedoria" (Ivone GEBARA, 1997, p. 33). Ora, a hierarquização do saber corresponde também a uma hierarquia social, fundada na exclusão das maiorias em favor da elite masculina branca que detém poder e saber. Simultaneamente, comporta uma dominação/submissão de classes sociais, de gênero e também étnica, pois se subestima os saberes negros e indígenas.

Ivone delineia alguns traços da epistemologia ecofeminista e sua percepção singular sobre o ser humano e sua relação com a Terra (Ivone GEBARA, 1997, p. 56-75). Tal incumbência apresenta riscos e certa provisoriedade, pois conhecer e (re)organizar o sentido da existência é tarefa sempre relativa e inacabada. Resumidamente:

(a) O fio condutor da epistemologia ecofeminista consiste em recuperar a experiência humana e deixar que aflore na mente e no corpo o significado de nossas crenças mais profundas.

(b) O ponto central é a interdependência entre todos os elementos que tocam o mundo humano, incluindo a natureza. Dilata-se a consciência para o Corpo Sagrado da Terra, maior que o eu individual, a fim de alargar nossa capacidade de respeitar e cuidar dele. Introduz-se nos processos educativos a perspectiva de comunhão com e não a de conquista da terra e do cosmos.

(c) A interdependência do conhecimento é vital, visceral, sagrada. Ela exige repensar a teologia cristã não a partir da vivência concreta das comunidades que experimentam o seguimento de Jesus em diferentes contextos. Leva-nos a pronunciar afirmações mais existenciais, humildes, aproximativas e dialogais.

(d) A epistemologia ecofeminista compreende uma "linearidade circular", no qual se resgata o passado e se abre ao futuro, acolhendo elementos de múltiplas formas, que não obedecem sempre à causalidade previsível. Processo contínuo como as peças de um caleidoscópio passível de novos arranjos. 
(e) A perspectiva ecofeminista leva ao desaparecimento dos dualismos "espírito x matéria" e "mente x corpo". Convida a viver a unidade de matéria e energia que nos constitui. Acolhe a finitude do humano e do cosmos, a beleza do efêmero. Busca formas de articular o público e o privado.

(f) Ela introduz a questão ecológica e a de gênero como mediações para compreender e interpretar o mundo e o ser humano. Superando o androcentrismo e quebrando o mito do "universalismo masculino", leva em conta a contribuição do masculino e do feminino na construção social do conhecimento.

(g) Essa epistemologia se desenvolve a partir de contextos locais, como referência básica, admitindo sua provisoriedade e a necessidade de abertura a novos referenciais, mais amplos. A epistemologia contextual mantém a tensão entre os aspectos local e universal do conhecimento humano.

(h) O ecofeminismo está fundado na visão holística: "somos num todo e o todo está em nós". Essa apela a diferentes capacidades cognitivas que habitam o humano e não se reduzem ao discurso único de tipo racionalista.

(i) Essa forma de conhecer é também afetiva, pois a partir do envolvimento apaixonado se percebem aspectos que antes seriam ignorados. $\mathrm{O}$ universo das emoções, longe de ser o lado obscuro da razão, é assumido como fonte de conhecimento. Somos uma mistura extraordinária de razão, emoção, sentimento, paixão e sedução. Essa mescla se manifesta em mulheres e homens em sua originalidade pessoal e nos contextos culturais, com seus condicionamentos.

(j) Por fim, a epistemologia ecofeminista é inclusiva. Conjuga diferentes padrões, acolhe diversos saberes, conecta-se com conhecimentos de diferentes áreas. Tal perspectiva é essencial para a teologia, pois a experiência religiosa é polifônica e multicolorida, e se expressa num leque amplo de linguagens, referidas a uma mesma respiração e busca de unidade (Ivone GEBARA, 1997, p. 56-75).

As afirmações de Ivone Gebara dizem respeito não somente ao ecofeminismo, mas também ao feminismo, na qual se radica. Este traz uma contribuição imprescindível para a cultura e a religião, como desenvolve o número especial da Revista Pistis e Práxis (2021), intitulado "Hermenêuticas do feminino". No editorial, se diz que o foco do pensamento feminino representa

(..) a crítica a uma racionalidade que tomou o neutro, o objetivo, o abstrato e o universal como norma do saber e do ser; uma racionalidade que reduziu o particular, o contextual, o diferente a perspectivas marginais. A valorização das diferenças deve potencializar a configuração de uma racionalidade aberta e integradora, um pensar que escute e respeite a realidade na sua profundidade abissal e na sua diversidade complexa (Ceci MARIANI et al., 2021, p. 3). 


\section{Interfaces de Ecofeminismo e Ecoteologia}

Acerca da ecoteologia convém destacar os escritos de Román GURIDI (2018), Ernest CONRADIE (2020) e as duas clássicas obras que praticamente inauguram a ecoteologia como reflexão sistemática, de Jürgen MOLTMANN (1987) e Leonardo BOFF (2002/2015). Já apresentamos um quadro panorâmico sobre a ecoteologia, sua singularidade, método, tipologias, principais temas, tarefas e a ecoespiritualidade, que não repetiremos aqui (Afonso MURAD, 2016, p. 205-237; 2019, p. 65-97; 2020, p. 519-540).

Como mostramos, o ecofeminismo, enquanto ativismo socioambiental feminino e corrente de pensamento é mais amplo do que a teologia ecofeminista. A segunda ressoa, acolhe, aprofunda e colabora na causa ecofeminista à luz da fé, em comunidades cristãs. Fato semelhante acontece com a ecologia, enquanto saber, paradigma e ética, e a ecoteologia. Na última parte do nosso trabalho ensaiaremos algumas respostas para a questão: como o ecofeminismo e a teologia ecofeminista, sobretudo quanto à hermenêutica e ao método, contribuem para o avanço da ecoteologia latino-americana e caribenha? Usar-se-á o estilo de breves teses, que poderão ser desenvolvidas em futuras pesquisas.

(a) A ecoteologia e a teologia ecofeminista não são duas correntes diferentes, que se contrapõem ou se diferenciam de forma contrastante. Diríamos que são águas do mesmo rio, com densidade própria. Faz lembrar o encontro das águas do rio Negro e do Amazonas, próximo a Manaus. Na verdade, muitas teólogas feministas são também ecoteólogas, participam do ativismo socioambiental e contribuem significativamente para o avanço da ecoteologia. No entanto, a recíproca parece não ser verdadeira. É raro encontrar um teólogo que se declara ecofeminista e se dedica à pesquisa dessa temática. Um teólogo branco, adulto, com um nível de vida razoável não tem medo de assumir o lugar social de afrodescendentes, povos originários e pobres. Não no lugar deles(as), mas junto com eles(as), favorecendo seu protagonismo. No entanto, soa até estranho que o faça com as mulheres e na defesa da causa ecofeminista. Está na hora de assumir o ecofeminismo como companheiro da ecoteologia, para homens e mulheres. Isso significa considerar a teologia ecofeminista não somente como uma vertente ou um conjunto de discursos que compõem a unidade plural da ecoteologia, mas também como um pensamento original, irredutível, que a questiona e enriquece enormemente.

(b) A teologia feminista e a ecoteologia latino-americanas, embora recebam contribuições fundamentais do primeiro mundo nas suas origens, elaboram um discurso próprio, com traços específicos do nosso continente. Ambas foram gestadas no ventre da Teologia da Libertação e compartilham suas intuições básicas, tais como: o lugar social que condiciona o lugar hermenêutico, o apelo a assumir o clamor dos(as) subalternos(as); a indignação 
diante das injustiças sociais; a dimensão comunitária e institucional da fé cristã; o protagonismo dos(as) oprimidos(as) em busca de libertação; o sonho de uma nova sociedade que supere as relações de dominação; a gestação de uma espiritualidade libertadora; a releitura da Bíblia e da Tradição eclesial com novo olhar; o resgate da sabedoria dos nossos povos e etnias; a articulação de teoria e prática, com prioridade na práxis transformadora; a incorporação das teorias críticas e o diálogo com várias ciências e áreas do saber. Gera-se, então, uma reflexão teológica socialmente libertadora, feminista e ecológica. Elas são necessárias, pois desentranham aspectos centrais do Evangelho e o atualizam (Geraldina CÉSPEDES, 2012, p. 69-72).

(c) A hermenêutica ecofeminista, em vários lugares do mundo, como no oriente asiático, no ocidente europeu e norte-americano, na África e na América Latina associou um leque crescente de autoras. Ela articula de forma criativa a tensão entre diversidade e unidade no essencial, encarnação nas realidades locais e visão universal. Esses fatores são imprescindíveis para alimentar a fraternidade-sororidade e a amizade social, como bem sinaliza o Papa Francisco na Encíclica Fratelli Tutti (FT, n. 142-153). Do ponto de vista da ciência da fé, ecoteologia e teologia feminista superam a categoria "de teologias contextuais", pois não se limitam a um grupo humano e eclesial delimitado por faixa etária, etnia, cultura, ou fronteiras geográficas. Contextualizadas, sim. Mas com um grau de universalidade crescente, rejeitando "o domínio de homogêneo, uniforme e padronizado de uma única forma cultural imperante" (FT, n. 144).

(d) $\mathrm{O}$ crescente impacto negativo do capitalismo neoliberal na vida das mulheres indianas, apontado por Vandana Shiva, encontra seu correspondente na exploração das mulheres campesinas e indígenas no nosso continente, sobretudo devido ao garimpo, à mineração, à destruição da Amazônia e de outros biomas, à implantação da monocultura de pinus e do eucalipto, e à substituição da agricultura tradicional pelo agronegócio. As mulheres pobres são as mais atingidas no seu cotidiano e nos seus corpos. De outro lado, é impressionante o empoderamento das mulheres através das práticas ecofeministas (Raquel QUESADA GUERRERO, 2010). Situação semelhante acontece com as mulheres das periferias urbanas de nossas cidades. Ao "esquecer" das mulheres, tanto como vítimas, quanto como protagonistas de transformação, a ecoteologia incorreu no mesmo equívoco do patriarcalismo, embora tenha uma intencionalidade libertária e libertadora. Atualmente, ao denunciar a destruição da nossa Casa Comum e seu impacto sobre a humanidade, especialmente os mais pobres, a ecoteologia aprende do ecofeminismo a diferenciar como isso acontece de maneira específica em mulheres e homens.

(e) O ecofeminismo se situa na intercessão de feminismo e ecologia. Algo semelhante se dá no campo teológico, coma teologia ecofeminista. Essa articula de forma original e criativa a questão de equidade de gênero e 
o cuidado da Casa Comum, à luz da fé. O compositor Betto Guedes, na música "Sal da Terra" diz que " $1+1$ é sempre mais que 2". Semelhante a uma relação amorosa, na qual cada parceiro(a) mantém sua identidade e ambos(as) crescem em interação, se apoiando mutuamente, assim é a relação da teologia feminista e a ecoteologia. Essa "união estável" favorece a ambas.

(f) A teologia ecofeminista denuncia o patriarcalismo na Igreja, que se traduz, entre outras coisas, por relações autoritárias e concentradoras de poder nas mãos de homens, monopólio da pregação na celebração eucarística, negação ao acesso do ministério ordenado para as mulheres, ritualismo que cerceia o corpo, pregação da doutrina sem emoção, falta de reconhecimento (invisibilização) da atuação das mulheres nas comunidades. Daí que a sinodalidade se torna vital para a Igreja. Especialmente se inclui a presença quantitativa e qualitativa das mulheres na Igreja e a necessidade de criar estruturas participativas, comunitárias e não piramidais.

(g) A presença de mulheres no Sínodo para a Amazônia contribuiu para incluir num conjunto articulado as diversas dimensões da ação evangelizadora, ao traçar novos caminhos de conversão pastoral, cultural, ecológica e sinodal (Sínodo para a Amazônia, 2019). O sínodo se compromete a ser Igreja samaritana, que assume a realidade bela e sofrida das pessoas e da natureza; Igreja Madalena, amada e reconciliada, que anuncie com alegria Cristo crucificado e ressuscitado; Igreja mariana que gera filhos para a fé e os educa com afeto e paciência, aprendendo com as riquezas dos povos (Sínodo para a Amazônia, n. 22). O documento final do Sínodo inaugura também algo que deve marcar a redação dos documentos eclesiais: visibilizar as mulheres. Em dois sentidos: como vítimas dos mecanismos de opressão (n. 10, 13, 34, 102) e enquanto sujeitos eclesiais e sociais (n. 71, 96, 92, 95, 99, 100, 101, 102, 103). Destacamos aqui quatro citações, das trinta que aparecem no documento sinodal: "As vítimas (da destruição da Amazônia pelo poder econômico e político) são os setores mais vulneráveis, crianças, jovens, mulheres e a irmã mãe terra" (n. 10); "A vida consagrada, os leigos e entre eles as mulheres, são os protagonistas antigos e sempre novos que nos chamam a esta conversão sinodal" (n. 86); "É urgente que a Igreja na Amazônia promova e confira ministérios para homens e mulheres de maneira equitativa (n. 95); "Diante da realidade sofrida pelas mulheres vítimas de violência física, moral e religiosa, incluindo o feminicídio, a Igreja se posiciona em defesa de seus direitos e as reconhece como protagonistas e guardiã" da criação" e da "casa comum" (n. 102). Que os apelos do Sínodo, especialmente o de conferir às mulheres o ministério de coordenadora de comunidade e avançar no diaconato feminino, não caiam no olvido.

(h) O papa Francisco, na Laudato si', propõe uma "conversão ecológica" (LS, n. 217), que se traduz simultaneamente em postura de vida (sobriedade feliz: 
LS, n. 222-227), espiritualidade (LS, n. 216), atitudes pessoais para ativar um cuidado generoso e cheio de ternura que se consolidam em hábitos (LS, n. 211, 220), ações coletivas com a formação de redes comunitárias (LS, n. 219) e o cultivo do amor civil e político que impele a adotar "grandes estratégias que detenham eficazmente a degradação ambiental e incentivem uma cultura do cuidado que permeie toda a sociedade" (LS, n. 231). Essa percepção a respeito da simultaneidade dos processos de mudança individuais e comunitários converge com as conviç̧ões da ecoteologia e da hermenêutica ecofeminista. Devemos acrescentar, à luz da visão da própria encíclica ("tudo está interligado", LS, n. 16, 91) e do Sínodo da Amazônia ("conversão integral", com várias dimensões, n. 17-19), que isso implica também uma "conversão de gênero". Faz parte desse processo de conversão: tomar consciência da mentalidade patriarcal, sexista, androcêntrica que ainda povoa nossas mentes e corações; reconhecer nossos pecados de ação e omissão, e, com a graça de Deus, trilhar novos caminhos. A conversão de gênero diz respeito a homens e mulheres, mas de maneira própria para cada um(a). Para os homens, tal conversão desperta nossa sensibilidade para superar preconceitos e aceitar novos papéis na relação com as mulheres, leva a compreender que as suas reivindicações de singularidade e igual dignidade beneficiam a toda a humanidade, colabora para a equidade de gênero; re-situa a nossa identidade e nos põe a tarefa fascinante e desafiadora de viver de outra maneira nossa masculinidade, não mais como dominação. Para todos(as), ressoa o apelo à mudança, da percepção arrogante para a amorosa.

(i) A categoria "cuidado", sistematizada e difundida por Leonardo Boff (2002) e universalizada na Laudato si' constitui uma chave de leitura central para a ecoteologia. Ela se mostra como o antídoto para o antropocentrismo egóico da modernidade, que considera todas as outras criaturas como "coisas" submetidas à supremacia humana. Ao cuidado se associa o reconhecimento do valor em si mesmo de cada criatura (LS, n. 33, 69), e a consciência de que somos parte da terra, a Casa Comum, na qual habitamos com bilhões de seres que compõem a criação. Esse planeta é para nós como uma irmã, com quem partilhamos a existência, e a mãe bondosa, que nos acolhe nos seus braços (LS, n. 1-2). Destacam-se, então, duas contribuições singulares da visão ecofeminista para a ecoteologia, nessa temática. Ela mostrou que as mulheres, não por uma característica da sua pretensa essência, mas devido aos contextos culturais de longo tempo, se consolidaram como as principais cuidadoras dos humanos e da natureza. As mulheres assumem grande parte dos cuidados relacionados à dimensão reprodutiva do ser humano. Não somente a gestação e amamentação, mas também a educação das crianças, a alimentação e a limpeza da casa. Mais ainda, elas constituem as principais cuidadoras dos doentes e dos idosos. Também, em grande parte do mundo, são as principais cultivadoras de verduras, legumes, grãos, frutas e flores de forma artesanal e agroecológica. Portanto, quando a ecoteologia discorre sobre o cuidado como atitude humana básica em relação ao nosso planeta, deve 
nomear a contribuição imprescindível das mulheres. Em segundo lugar, a hermenêutica ecofeminista acrescenta a imagem da Terra como corpo, o que abre outras perspectivas interpretativas. Ela afirma que a mesma atitude básica se manifesta de maneiras diferentes e complementares, no cuidado com o próprio corpo, com o corpo dos outros(as) e o corpo da Terra, da qual fazemos parte.

(j) A reflexão feminista traz uma contribuição ímpar para a superação da herança patriarcal que contagiou a teologia cristã, ao resgatar e propor dimensões femininas de imagem de Deus. É preciso superar as representações androcêntricas de Deus, como a do velho solitário de barbas brancas a vigiar e castigar, o Deus masculino todo-poderoso. Não se trata de substituir deus pela deusa. Elizabeth JOHNSON brindou-nos uma reflexão original na obra "Aquela que é: o mistério de Deus no trabalho teológico feminino" (1995). Ela apresenta um modelo de linguagem cristã feminista que surge de diversas experiências: a presença universal vivificante e libertadora do Espírito, a sabedoria em Jesus de Nazaré, que também cria e orienta o universo. Tais imagens se aglutinam no símbolo da trindade, comunhão viva de relacionamentos interpessoais mútuos e iguais. A comunidade trinitária não é impassível, pois participa do sofrimento do mundo, em vista de sua redenção. A essa perspectiva teológica se soma a reflexão de Sallie McFAGUE (1996). Ela propõe metáforas contemporâneas de Deus como mãe/pai, amante e amigo(a) dos últimos, de maneira a caracterizar o evangelho cristão como amor radical e surpreendente. Tais representações tríduas evocam as atividades divinas de criar, salvar e sustentar, em relação à natureza e à humanidade. Elas expressam o amor inteiro, unitivo e recíproco de Deus ao mundo. A vida em toda sua extensão é como o corpo de Deus (mas não se identifica com Ele/Ela). Deus-amante considera o mundo atraente e precioso, como os amantes aos seus amados. A metáfora do Deus-amigo(a) representa-o como fiel companhia, que opera conosco a cura de todas as partes do corpo do mundo. Deus conta com nossa colaboração para estender a plenitude a toda a criação. Cada traço do único amor divino sugere uma dimensão do discipulado cristão: justiça (ágape), cura (eros) e companheirismo (filia) (Sallie McFAGUE, 1996, p. 133-134). Então, a ecoteologia somente será consequente se deixar fecundar em seu discurso uma imagem libertadora de Deus, tal como a realiza o ecofeminismo cristão.

(1) O desenvolvimento da ecoteologia requer uma série de frentes de atuação, em termos de aprofundamento bíblico, resgate da Tradição eclesial, diálogo inter-religioso, interação com outras áreas do conhecimento, escuta e sistematização de iniciativas socioambientais bem-sucedidas, relação de outras teologias libertadoras (como as indígenas e afroamericanas). Para disseminar sua visão, de forma a incidir na vida das Igrejas e na sociedade, a ecoteologia necessita utilizar não somente conceitos, mas também analogias, poesia e histórias de vida. Seu discurso deve cada vez mais veicular uma racionalidade cordial, da razão encharcada de emoção. Recorrer às narrativas, 
que contam as histórias humanas, para mostrar como somos ecodependentes, interdependentes e responsáveis pelo cuidado da casa comum. Nessa empreitada, a teologia feminista tem muito a nos ensinar. No que diz respeito à ecoespiritualidade, as mulheres experimentam Deus de maneira diferente dos homens, oram com o corpo, dançam em louvor. Essas e tantas outras aprendizagens serão decisivas para o presente e o futuro da ecoteologia.

\section{Conclusão}

O ecofeminismo, enquanto vigorosa corrente de pensamento e criativo movimento socioambiental, contribui para superar dicotomias e reconstruir o ser humano na sua corporeidade, ecodependência e interdependência, na perspectiva da diversidade de gênero. Usando a analogia de Lúcia CARBONELL (2014), assemelha-se a um cruzamento de trânsito, na qual confluem pessoas e coletivos, que vem de vias diversas, como o ativismo ecológico e feminista, o mundo acadêmico e as religiões. Por lá circulam grupos locais e redes internacionais. Acrescentemos algo mais. No meio do cruzamento circular, que está no alto do monte, há uma enorme e bela praça. Nela erguem-se majestosas árvores, que a seu tempo florescem. Há também mangueiras e goiabeiras, que oferecem seus doces frutos. Pássaros repousam em seus galhos e se abrigam sob sua sombra. Crianças brincam nos espaços verdes. Jovens inundam o ambiente com suas gargalhadas e vozerio alto. Anciãos e anciãs contam histórias, enquanto se aquecem com o sol da manhã. Um casal jovem passeia com o carrinho de bebê. $\mathrm{O}$ frescor do vento, qual a ruah divina, alenta e anima as pessoas que aí passeiam. Nessa praça se faz e se celebra a ecoteologia e a teologia ecofeminista.

\section{Siglas}

$\mathrm{FT}=$ Fratelli tutti

$\mathrm{LS}=$ Laudato $\mathrm{si}^{\prime}$

\section{Referências}

ADICHIE, Ch. N. Sejamos todos feministas. São Paulo: Companhia das Letras, 2015. AGUILLA, E. Con-spirando juntas. Con-spirando, Santiago, n. 1, p. 2-5, mar. 1992. AZCUY, V. R; DI RENZO, G.; MENDONZA, C. A. L. (Orgs.). Diccionario de obras de autoras en América Latina, el Caribe y Estados Unidos: Mujeres haciendo teologías. Buenos Aires: San Pablo, 2007. v. 1.

AZCUY, V. R.; DI RENZO, G.; MENDONZA, C. A. L. (Orgs.). Antología de textos de autoras en América Latina, el Caribe y Estados Unidos: Mujeres haciendo teologías. Buenos Aires: San Pablo, 2008. v. 2. 
AZCUY, V. R; DI RENZO, G.; MENDONZA, C. A. L. (Orgs). Estudio de autoras en América Latina, el Caribe y Estados Unidos: Mujeres haciendo teologías. Buenos Aires: San Pablo, 2009. v. 3.

BINGEMER, M. C. L. Teologia latino-americana: raízes e ramos. Petrópolis: Vozes, 2017.

BOFF, L. Saber cuidar: ética do humano, compaixão pela terra. 8.ed. Petrópolis: Vozes, 2002.

BOFF, L. Ecologia: grito da Terra, grito dos pobres. 2.ed. atualizada. Petrópolis: Vozes, 2015.

$\mathrm{BOSCH}, \mathrm{A}$. et al. Verde que te quiero violeta: encuentros y desencuentros entre feminismo y ecologismo. 2003. Disponível em:<https://www.fuhem.es/media/cdv/ file/biblioteca/Boletin_ECOS/10/verde_que_te_quiero_violeta.pdf $>$. Acesso em: 07 jul. 2021.

BUARQUE DE HOLANDA, H. (Org.). Pensamento feminista hoje: perspectivas decoloniais. Rio de Janeiro: Bazar do Tempo, 2020.

CARBONNEL, L.R. Ecofeminismos y teologías de la liberación. Papeles, Madrid, n 125, p. 101-109, 2014. Disponível em: <https://www.fuhem.es/papeles/papeles-numero-125/>. Acesso em: 07 nov. 2021.

CÉSPEDES, G. Correntes fecundando una misma tierra. Teología de la liberación y teología feminista. Alternativas, Manágua, v. 19, n. 44, p. 69-88, jul./dez. 2012.

COLECTIVO EDITORIAL, Con-spirando, Santiago, p. 1, mar. 1992.

CONRADIE, E. M. The four tasks of christian ecotheology: revisiting the current debate. Scriptura, Stellenbosch, v. 119, n. 1, p. 1-13, 2020.

D’EAUBONNE, F. Le féminisme ou la mort Femmes en mouvement. Paris: Pierre Horay, 1974.

DÍAZ ESTÉVEZ, A. Ecofeminismo: poniendo el cuidado en el centro. ENE - Revista de Enfermería, Madrid, v. 13, n. 4, dic. 2019. Disponível em: <http://ene-enfermeria. org/ojs/index.php/ENE/article/view/1072>. Acesso em 07 nov. 2021.

DOWBOR, L. A burrice no poder. In: VV.AA. Novos paradigmas para outro mundo possível. Rio de Janeiro: Usina, 2019. p. 9-34.

DOWBOR, L. A era do capital improdutivo. São Paulo: Outras palavras \& Autonomia literária, 2017.

FRANCISCO, Papa. Carta Encíclica Laudato Si': sobre o cuidado da Casa Comum. São Paulo: Paulinas, 2015.

FRANCISCO, Papa. Carta Encíclica Fratelli Tutti: sobre a fraternidade e a amizade social. São Paulo: Paulinas, 2020.

GANDON, A.-L. L'écoféminisme: une pensée féministe de la nature et la sociétè. Recherches féministes, Quebec, v. 22, n.1, p. 5-25, 2009.

GEBARA, I. Teologia ecofeminista: ensaio para repensar o Conhecimento e a Religião. São Paulo: Olho d'água, 1997.

GURIDI, R. Ecoteología: hacia un nuevo estilo de vida. Santiago: Ed. Universidad Alberto Hurtado, 2018. 
HERRERO, Y. et al. (Orgs.). Cambiar las gafas para mirar el mundo: una nueva cultura de la sostenibilidad. Madrid: Ecologistas en acción, 2011.

HERRERO, Y. Miradas Ecofeministas para transitar a un mundo justo y sostenible. Revista de Economia Crítica, Barcelona, n. 16, p. 278-307, 2013.

HURTADO, J. Retomando las palabras: rito. Con-spirando, Santiago, n. 1, p. 36-37, 1992.

JOHNSON. E. Aquela que é: o mistério de Deus no trabalho teológico feminino. Petrópolis: Vozes, 1995.

LÓPEZ BELLOSO, M.; SILVESTRE CABRERA, M.; GARCÍA MUÑOZ, I. Igualdad de Género en instituciones de educación superior e investigación. Investigaciones Feministas, Madrid, v. 12 n. 2, p. 263-270, 2021. Disponível em: <https://revistas. ucm.es/index.php/INFE/issue/view/3830>. Acesso em: 07 nov. 2021.

MARIANI, C. et al. Hermenêuticas do Feminino: por um esforço arqueológico e interdisciplinar para a recuperação da contribuição feminina no campo da cultura e da religião. Pistis \& Praxis, Curitiba, v. 13, p. 1-14, 2021. Editorial.

McFAGUE, S. Modelos de Deus: teologia para uma era ecológica e nuclear. São Paulo: Paulus, 1996.

MOLTMANN, J. Dios en la Creación. Salamanca: Sígueme, 1987.

MURAD, A. Singularidade da ecoteologia. In: MURAD, A. (Org.) et al. Ecoteologia: um mosaico. São Paulo: Paulus, 2016. p. 205-237.

MURAD, A. Da ecologia à ecoteologia: uma visão panorâmica. Fronteiras, Recife, v. 2, n. 1, p. 65-97, jan./jun. 2019.

MURAD, A. Ecoteologia: ciência da fé e espiritualidade. Pistis E Praxis, Curitiba, v. 12, n. 3, p. 519-540, set./dez. 2020.

NAREDO, J. M. Raíces económicas del deterioro ecológico y social: más allá de los dogmas. Madrid: Siglo XXI, 2006.

PULEO, A. H. Ecofeminismo para otro mundo posible: feminismos. Madrid: Cátedra, 2011.

PULEO, A. H. El patriarcado: ¿una organización social superada? Mujeres en Red, 2006. Disponível em: <https://www.mujeresenred.net/spip.php?article739>. Acesso em: 07 nov. 2021.

PULEO, A. H. Luces y sombras del ecofeminismo. Asparkía Investigació Feminista, Barcelona, n. 11, p. 37-45, 2002a.

PULEO, A. H. Un repaso a las diversas corrientes del ecofeminismo: feminismo y ecologia. Ecopolítica, Madrid, n. 31, Verão de 2002b. Disponível em: <https:// ecopolitica.org/un-repaso-a-las-diversas-corrientes-del-ecofeminismo-feminismo-y-ecolog/>. Acesso em: 07 nov. 2021.

PULEO, A. H. Mujeres por un mundo sostenible. Dossiers Feministes, Castelló de la Plana (Catalunha), n. 14, p. 9-19, 2010.

QUESADA GUERRERO, R. Empoderamiento de mujeres latinoamericanas através de prácticas ecofeministas. Investigaciones Feministas, Madrid, v. 1, p. 97-109, 2010. 
Disponível em: <https://observatorio.aguayvida.org.mx/media/empoderamiento-de-mujeres-latinoamericanas-a-traves-de-practicas-ecofeministas.pdf $>$. Acesso em: 07 nov. 2021.

RUETHER, R. R. Ecofeminismo: Mulheres do Primeiro e do Terceiro Mundo. Estudos Teológicos, São Leopoldo, n. 36, p. 129-139, 1996.

SANTISO, M. T. P. La mujer, espacio de salvación: misión de la mujer en la Iglesia, una perspectiva antropológica. Madrid: Claretianas, 1995.

SCHÜSSLER FIORENZA, E. Caminhos de sabedoria: uma introdução à Interpretação Bíblica Feminista. São Bernardo: Nhanduti, 2009.

SHIVA, V.; MIES, M. Ecofeminismo: teoría, crítica y perspectivas. Madrid: Icaria, 2016.

SÍNODO PARA A AMAZÔNIA. Documento final. Amazônia: Novos Caminhos para a Igreja e para uma Ecologia Integral, 2019. Disponível em: $<$ http://secretariat. synod.va/content/sinodoamazonico/pt/documentos/documento-final-do-sinodo-para-a-amazonia.html>. Acesso em: 07 nov. 2021.

TAVARES, M. Ecofeminismo(s). Centro de Documentação e Arquivo Feminista Elina Guimarães, 2014. Disponível em: <https://www.cdocfeminista.org/wp-content/ uploads/2014/02/ECOFEMINISMO_Manuela_Tavares_5fev2014UF.pdf $>$. Acesso em: 07 nov. 2021.

TRAPASSO, R. D. Potenciar el futuro, colectivamente. Revista Con-spirando, Santiago, n. 1, p. 6-10, mar. 1992.

WARREN, K. J. El poder y la promesa del feminismo ecológico. In: VALDÉS, M. M. (Org.). Naturaleza y valor: una aproximación a la ética ambiental. México: Fondo de cultura económica, 2004. p. 233-261.

Artigo submetido em 15.09.2021 e aprovado em 29.11.2021.

Afonso Murad é doutor em teologia pela Universidade Gregoriana. MBA em tecnologias e gestão ambiental no PECE da Universidade de São Paulo (USP). Ambientalista. Professor de teologia e pesquisador em ecoteologia e mariologia na FAJE. Bolsista em produtividade e pesquisa do CNPq. Orcid.org/0000-0002-3714-7378. E-mail: murad4@hotmail.com

Endereço: Av. Dr. Cristiano Guimarães, 2127

Planalto

31.720-300 Belo Horizonte - MG 